\title{
Vagus Nerve Stimulation for the management of depression: Rationale, anatomical and physiological basis of efficacy and future prospects
}

\author{
Metin Tulgar ${ }^{1}$, Erol Ozan $^{2 *}$, Zafer $\mathrm{Akan}^{3}$
}

\section{Dear Editor,}

Treatment-resistant depression (TRD) is a major public health concern due to its high costs to society. One of the novel approaches for the treatment of depression is the Vagus Nerve Stimulations (VNS). Therapeutic brain stimulation through delivery of pulsed electrical impulses to the left cervical vagus nerve now has established safety and efficacy as an adjunct treatment for medication-resistant epilepsy (1).

Vagus nerve stimulation therapy is US FDA approved for the adjunctive treatment of epilepsy and has also been applied for the medication resistant depression (2-6). Owing to its novel route into the brain, it has no drug-drug interactions or systemic side effects. This treatment also appears to have high long term tolerability in patients, with low rates of patients relapsing on Vagus nerve stimulation or becoming tolerant.

However, alongside the excitement and enthusiasm for this new treatment, a lack of Class I evidence of efficacy in treatment depression is currently slowing down adoption by psychiatrists.

Much more research is needed regarding exactly how to refine and deliver the electrical pulses and how this differentially affects brain function in health and disease.

In this clinical study, 10 patients ( 7 women, 3 men) who have diagnosis of major depression, the ages of patients are between 31 and 44. After two years follow up, the patients' Hamilton depression scores have been improved significantly.
In the present literature, heavy cases are advised to be excluded (7). Very interestingly, in this study a 44 year old lady, who was repeatedly talking about suicide, soon after the activation of the vagal nerve implant rescued.

As to our first prelaminar report about Vagus nerve stimulators and management of depression indicate that, VNS treatment may be an alternative to treatment for major depression patients.

\section{References}

1. Tulgar M, Bilgin S, Yildirim A. The Human Body's Own Language to be Considered for Safe and Effective Neurostimulation. Neurol Ther. 2012; 1:2-7.

2. Rush AJ, George MS, Sackeim A, et al. Vagus nerve stimulation (VNS) for treatment-resistant depressions: a multicenter study. Biol Psychiatry. 2000;47(4):276-286

3. Sackeim HA, Rush AJ, George MS, et al. Vagus nerve stimulation (VNS) for treatment-resistant depression: efficacy, side effects, and predictors of outcome. Neuropsychopharmacology 2001;25(5):713-728

4. Schlaepfer TE, Frick C, Zobel A, et al. Vagus nerve stimulation for depression: efficacy and safety in a European study. Psychol Med. 2008; 38(5):651-61.

5. Sperling W, Reulbach U, Kornhuber J. Clinical benefits and cost effectiveness of vagus nerve stimulation in a longterm treatment of patients with major depression. Pharmacopsychiatry 2009;42(3):85-88.

6. Nierenberg AA, Alpert JE, Gardner-Schuster EE, et al. Vagus nerve stimulation: 2-year outcomes for bipolar versus unipolar treatment-resistant depression. Biol Psychiatry. 2008; 64(6):455-60. 